SlavVaria 1/2021. 87-98

DOI: $10.15170 /$ SV.1/2021.87

\author{
ДИАНА КОМЯТИ
}

(Печ, Венгрия)

\title{
«Два романа одного жизнеописания»: «Три года» А.П. Чехова и «Братья Карамазовы» Ф.М. Достоевского ${ }^{1}$
}

Аннотация: В современном чеховедении все более осмысливается значение творческого наследия Достоевского в художественном мире Чехова, предлагаются попытки раскрытия и интерпретации интертекстуальных связей с творчеством Достоевского, заложенных в подтексте чеховских произведений. Выявляются, с одной стороны, общие темы и проблемы, сближающие писателей, с другой - отмечается полемическое переосмысление Чеховым наследия Достоевского. В русле этой тенденции в настоящей статье проводится сопоставительный анализ повести Чехова «Три года» и романа Достоевского «Братья Карамазовы», и предпринимается попытка выявления и прочтения скрытых в чеховской повести аллюзий и параллелей.

Ключевые слова: Чехов, Достоевский, интертекстуальность, художественная антропология, личность

Долгое время вопрос о межтекстуальных связях творчества Чехова и Достоевского оставался на периферии литературоведения, а если и рассматривался исследователями, то только вскользь, ограничиваясь, как правило, общими замечаниями по поводу насмешливого и критического отношения Чехова к «манере» Достоевского, пародийных обыгрываний и иронических снижений (ранним) Чеховым образов, мотивов и сцен произведений великого предшественника. Перефразируя одного из чеховских героев, получалось так, что «Достоевский сам по себе, а Чехов сам по себе».

Разумеется, подобное отношение к вопросу «Чехов - Достоевский» возникло не случайно. Уже современники обратили внимание на явную противоположность двух писателей: отмечалось прежде всего отступление Чехова от традиций классиков, сравнивались - и, конечно же, не в пользу младшего писателя - вера и поиски истины у Достоевского и атеизм Чехова, первостепенное значение «идеи» в художественном мире первого и безыдейность второго, захватывающая интрига здесь и бессобытийность там. В результате, начиная с современной

1 В статье частично используются ранее не опубликованные материалы диссертации, выдвинутой на соискание ученой степени $\mathrm{PhD}$ в 2018 г. 
Чехову критики прочно и надолго укоренилось мнение о невозможности даже «насильственно сблизить двух писателей, Достоевского и Чехова, которые не имеют между собой ни одной общей черты, ни как люди, ни как художники, ни как „пророки” (КРАЙНИЙ: URL)². Сам Чехов тоже не очень-то помог ни современникам, ни последующим поколениям исследователей разобраться в этом вопросе - как известно, о Достоевском писатель высказывался крайне редко и весьма сдержанно. ${ }^{3}$

Тем не менее, в чеховедении стал постепенно осмысливаться вопрос о значении художественного наследия Достоевского в творчестве Чехова. Обратили на себя внимание пародийные обыгрывания тем и «манеры» Достоевского - прежде всего в ранних чеховских вещах -, как напр. сатирическая сценка «Загадочная натура» (1883) или повесть «Драма на охоте» (1884), в которой бросается в глаза нарочитое использование повествовательного стиля Достоевского (ПОЛОЦКАЯ 1971: 189). Также не могли исследователи пройти мимо прямых ссылок на Достоевского и его героев в чеховских произведениях, таких как напр. упоминание Раскольникова в той же «Загадочной натуре» или высказывание «странный брак во вкусе Достоевского» в характеристике героя рассказа «Соседи» (1892). Однако уже советское литературоведение стало осознавать, что за пародийным отношением Чехова к Достоевскому скрывается отношение не совсем простое, только усложняющееся по мере созревания Чехова как художника, и предпринимались попытки раскрытия более сложных и глубоких соотношений между писателями - к таким попыткам можно отнести указанную выше статью Полоцкой. В настоящее время наблюдается сдвиг в направлении к переосмыслению интертекстуальных взаимосвязей, стремление раскрыть в глубинных пластах чеховских произведений диалог с наследием Достоевского. Как формулирует Р. Назиров, «Чехов скромно, но твердо оспаривал Достоевского. Однако в силу чрезвычайной широты и всемирности проблематики Достоевского между обоими писателями оставалось и немало общего, объединяющего (...) Таким образом, Чехов возражал Достоевскому и спорил с ним, одновременно продолжая его темы и развивая некоторые важнейшие идеи» (НАЗИРОВ 2005: 168). Тем не менее, многое из этого «общего» все еще остается невыясненным, поэтому цель настоящей статьи - предпринять попытку выявления скрытых в подтексте чеховского произведения аллюзий и параллелей, связывающих повесть «Три года» с романами Достоевского, и предложить возможную интерпретацию обнаруженных интертекстуальных связей.

\footnotetext{
2 Подробнее о постановке вопроса «Чехов-Достоевский» в литературной критике начала ХХ века см. ПОЛОЦКАЯ 1971: 186-189.

${ }^{3}$ Немногочисленные высказывания Чехова о Достоевском подробно приводятся Бердниковым: БЕРДНИКОВ 1984: 107-109; 111.
} 
Прежде чем перейти, собственно, к предмету настоящего исследования, считаем нужным оговориться, что выявление взаимосвязей чеховских произведений с творческим наследием Достоевского ставит перед нами весьма непростую задачу, сложность которой заключается в том, что в силу особенностей творческого метода Чехова эти взаимосвязи - в особенности в зрелый период творчества - обыкновенно скрываются писателем, являются практически неразличимыми в тексте. Ключом к обнаружению скрытых намеков у Чехова, как правило, служат так называемые «случайные» детали (Чудаков), то есть незначительные, неприметные, немотивированные элементы художественного мира, оказывающиеся, в конечном итоге, вовсе не случайными. Как верно замечает Громов, «чеховский художественный текст представляет собой систему подразумеваний и соответствий; как бы сложна эта система ни была, она заключает в себе все необходимое для понимания; мало сказать, что в ней нет ничего лишнего - она застрахована от излишеств и всякого рода случайных нарушений ее внутреннего смысла и равновесия» (ГРОМОВ 1989: URL). Чехов как бы вовлекает читателя в своего рода интеллектуальную игру, в которой задействуется литературная память реципиента, необходимая для декодирования скрытых цитат и намеков. Именно поэтому мы ни в коем случае не решаемся утверждать, что в настоящем исследовании в полной мере раскрываются интертекстуальные связи чеховской повести и произведений Достоевского, напротив, с полным убеждением можно сказать, что дальнейшие исследования обязательно должны выявить новые созвучия и параллели ${ }^{4}$.

В повести «Три года» мы не встретим ни упоминания имени Достоевского или его героев, ни прямых или косвенных ссылок и цитат из его произведений. Тем не менее, при внимательном прочтении в тексте повести обнаруживаются несколько деталей, которые могут стать отправными точками в раскрытии и анализе интертекстуальных связей чеховского произведения и романов Достоевского. Так, старший брат Алексея Лаптева, Федор, человек посредственный, страдающий душевной болезнью, сочиняет свою первую статью под названием «Русская душа». Заглавие и содержание этой статьи, автор которой утверждает, что «интеллигентный человек имеет право не верить в сверхъестественное, но он обязан скрывать это свое неверие, чтобы (...) не колебать в людях веры; без веры нет идеализма, а идеализму предопределено спасти Европу и указать человечеству настоящий путь» (ЧЕХОВ 1977б: 80), выявляет отдаленную связь с романом Достоевского «Бесы»: как отмечается в комментарии к повести «Три года» в Полном собрании сочинений и писем Чехова, «в содержании статьи Федора Лаптева „Русская душа” есть от-

\footnotetext{
${ }^{4}$ Выявленные ранее интертекстуальные связи, не вошедшие в настоящую статью, напр. соотнесенность образа Юлии Белавиной с Хромоножкой Достоевского см. КОМЯТИ 2018: 70-77.
} 
звуки идей славянофильского и почвеннического толка. Мысль об исключительности русской души особенно характерна для поздних славянофилов (...), [которые] гибель Европы считали неизбежной и писали об историческом призвании России, опираясь на православие, как на спасительное свойство русского духа. Федор Лаптев (...) защищает религию с этих же позиций. Ср. также в „Бесах” Достоевского слова Шатова о народе-,богоносце”, призванном спасти мир (часть II, глава первая)» (ЧЕХОВ 1977б: 459).

Гораздо более существенным, однако, является то, что в составе и истории московской купеческой семьи Лаптевых усматриваются элементы, позволяющие соотнести это семейство с так называемым «случайным семейством» ${ }^{5}$ Достоевского - семьей, в которой, по мысли писателя, «распались внутренние связи и которая находится в состоянии „хаоса” и „беспорядка” (ДОСТОЕВСКИЙ 1994: 427). Мотив «случайного семейства» появляется уже в «Подростке», и, пройдя через все творчество Достоевского, наиболее полное художественное оформление получает в семейном романе «Братья Карамазовы». В «семейной повести» Чехова также изображается семья, в которой разлагаются внутренние связи, члены которой страдают от отсутствия любви, взаимопонимания и душевной теплоты. Сопоставляя семейства Лаптевых и Карамазовых, можно обнаружить весьма любопытные сходства: так, глава семейства Лаптевых, старик Федор Степаныч, как и Федор Павлович Карамазов - деспот и самодур, тиранящий свою семью, причиняющий множество страданий - физических и душевных - своим детям. У старика Лаптева также трое детей, среди них младший сын Алексей, родившийся, как и Алексей Карамазов, от затравленной, запуганной матери. О своей семье Алексей Лаптев рассказывает так: «Отец женился на моей матери, когда ему было сорок пять лет, а ей только семнадцать. Она бледнела и дрожала в его присутствии. Нина родилась первая, родилась от сравнительно здоровой матери (...), я же и Федор были зачаты и рождены, когда мать была уже истощена постоянным страхом» (ЧЕХОВ 1977б: 39; курсив мой - К.Д.). Нельзя не заметить созвучия между семейными обстоятельствами Лаптевых и Карамазовых: старик Карамазов женился на своей второй жене, матери Алеши, «с самого детства запуганной молодой женщине», когда ей было всего шестнадцать лет, Нина ${ }^{6}$, как и старший из братьев Карамазовых,

5 Появление мотива «случайного семейства» в произведениях Чехова, прежде всего в «Безотцовщине», уже раннее было замечено исследователями. См. по этой теме напр. САБО 2016; ЛИТОВЧЕНКО 2017.

6 На основе приведенных параллелей можно высказать предположение, что «замена» в чеховской повести старшего брата, Дмитрия Карамазова на женский образ (Нина) не случайна, так как образ Дмитрия также несет в себе женское начало: по свидетельству Вяч. Иванова, в этом герое Достоевского 
Дмитрий, отличается от двух младших братьев тем, что родилась она от «другой» («здоровой» $\left.{ }^{7}\right)$ матери, тогда как Федора и Алексея Лаптевых, подобно Ивану и Алексею Карамазовым, объединяет «общее происхождение» от больной, истощенной матери. К моменту действия повести мать Алексея Лаптева давно уже умерла, что также укрепляет соотнесенность чеховского героя с Алешей Карамазовым, тогда как душевная болезнь среднего брата, Федора, и его принадлежность (пусть только мнимая) к русской интеллигенции вызывает ассоциации с образом Ивана Карамазова.

Как явствует из приведенных выше параллелей, от семьи Лаптевых тянутся нити, с одной стороны, к «Подростку» и «Братьям Карамазовым» Достоевского, с другой же - к личному опыту и воспоминаниям Антона Павловича. В «случайном семействе» Достоевского Чехов легко мог увидеть сходства с историей своей собственной семьи ${ }^{8}$, и эту историю «вписать» в повествование о купеческом семействе Лаптевых. В этом плане заслуживают внимания созвучия между воспоминаниями Чехова, содержащимися в эпистолярии писателя, с признаниями его героя, Алексея Лаптева: «Детство отравлено у нас ужасами, нервы скверные до гнусности» (ЧЕХОВ 1977а: 198); «Деспотизм и ложь исковеркали наше детство до такой степени, что тошно и страшно вспоминать» (ЧЕХОВ 1976: 122) - пишет Чехов, а его герой признается: «мне припоминается мое детство и становится жутко» (ЧЕХОВ 1977б: 39), «Деда нашего помещики драли...», «Какие нервы и какую кровь мы получили в наследство?», «с детства я забит и запуган» (там же: 80 ).

Продолжая анализ интертекстуальных связей чеховской повести с романом «Братья Карамазовы», отметим одну, на первый взгляд случайную, деталь, которая, однако же, с точки зрения данного исследования

устанавливается таинственная связь с Деметрой, Матерью-Землей (ИВАНОВ 1989: 573).

7 Ср. характеристика Аделаиды Ивановны, матери Дмитрия: «дама горячая, смелая, смуглая, нетерпеливая, одаренная замечательною физической силой» (ДОСТОЕВСКИЙ 1991: 10).

${ }^{8}$ В этой связи весьма ценными являются замечания М. Литовченко о возможных читательских впечатлениях Чехова, связанных с «Подростком»: «В шестнадцатилетнем возрасте Антона оставили одного в Таганроге, и он был вынужден самостоятельно вырабатывать себе идею жизнестроительства, начиная с заботы о куске хлеба и кончая выбором жизненного пути. Он вполне мог находиться в числе корреспондентов Достоевского, узнавших себя в „Подростке” (...)

В связи с этим укажем ещё на одно совпадение - хронологическое: переезд Чеховых из Таганрога в Москву и начало „уединенной” юности Антона относятся к 1876 г. „Подросток” Достоевского печатался в 1875 г., отдельным изданием вышел в 1876, поэтому, будучи прочитанным, должен был произвести неизгладимое впечатление.» (ЛИТОВЧЕНКО 2017: 506). 
приобретает весьма существенное значение: речь идет об определении Лаптевым своего «именитого» рода как «мы, чумазые» (там же: 75). Эпитет «чумазый» в контексте ранее выявленных параллелей относит нас к этимологии фамилии Карамазовых, связанной, как известно, с тюркским кара - 'черный' + мазать, то есть Карамазов в «переводе» означает 'вымазанный черным', 'черномазый', синонимом которого, в значении 'грязный, запачканный', является чумазый. Таким образом, в чеховском произведении формируется еще одна аллюзия на роман «Братья Карамазовы», позволяющая, наряду с приведенными выше, установить однозначную соотнесенность повести «Три года» с последним романом Достоевского. А если так, то на основе всего вышесказанного образ «младшего сына», Алексея Лаптева может восприниматься как своего рода продолжение истории Алеши Карамазова, его жизнь «в миру». В качестве подтверждения этой мысли может служить воспоминание Лаптева в начале повести о том далеком времени, когда он еще верил в Бога: «...это напомнило ему время, когда он тоже веровал в бога и ходил ко всенощной и когда мечтал много о чистой, поэтической любви» (там же: 8, курсив мой - Д. К.).

Если с этой точки зрения взглянуть на повесть «Три года», то выплывают на поверхность весьма любопытные хронологические детали, в которых своеобразно переплетается реальное и повествовательное время. Так, роман Достоевского вышел в печати в 1880 г., и по свидетельству повествователя Алеше Карамазову в момент действия «первого» романа было 20 лет (см. «Братья Карамазовы», ч. I, кн. 1, гл. IV), второй же - «главный» - роман, согласно авторскому замыслу, отделен от событий первого тринадцатью годами ${ }^{9}$, то есть Алеше во втором романе должно было быть 33 года (принимая во внимание мировоззрение Достоевского, это - совершенно очевидное указание на возраст Христа). Повесть Чехова вышла в печати в январе 1895 г., но писалась она осенью 1894 г., то есть через четырнадцать лет после выхода «Братьев Карамазовых». Примечательно, что Алексею Лаптеву в повести 34 года, а поскольку в чеховском произведении нет прямых указаний на хронологические рамки повествования, то время действия повести можно воспринимать, как «настоящее» время писателя. Из этого следует, что если Лаптеву в год создания повести (1894 г.) исполнилось 34 года, то в 1880 г., в год выхода «Братьев Карамазовых», ему было 20 лет, точно так же, как и герою Достоевского. Конечно, эта хронологическая игра значительно усложняется тем обстоятельством, что в романе

9 См. в Предисловии к роману: «...жизнеописание-то у меня одно, а романов два. Главный роман второй - это деятельность моего героя уже в наше время, именно в наш теперешний текущий момент. Первый же роман произошел еще тринадцать лет назад, и есть почти даже и не роман, а лишь один момент из первой юности моего героя» (ДОСТОЕВСКИЙ 1991: 6). 
Достоевского рассказывается о событиях тринадцатилетней давности, тем не менее, учитывая приведенные выше хронологические «совпадения», а также установленные выше взаимосвязи между произведениями, роман Достоевского и чеховскую повесть можно рассматривать как «два романа одного жизнеописания», в котором «Братья Карамазовы», как подчеркивает сам автор, есть «один момент из первой юности моего героя», а «Три года» - «это деятельность (...) героя уже в наше время, именно в наш теперешний текущий момент» (ДОСТОЕВСКИЙ 1991: 6).

В образе Алексея Лаптева Чехов, с одной стороны, предлагает свой вариант продолжения истории Алеши Карамазова, по-своему «дописывая» роман, не законченный Достоевским. С другой стороны, «жизнь в миру» в данном контексте можно понимать и совсем почеховски, как перенесение возвышенного, «христоподобного» образа Алеши в повседневный «мир» обыкновенного человека. Здесь наблюдается та особенность творческого метода Чехова и его диалога с великим предшественником, замеченная многими исследователями, которая заключается в снижении, снижающей трансформации мотивов Достоевского (НАЗИРОВ 2005: 164), «приземлении, обытовлении ситуаций и действий героев, у Достоевского окруженных атмосферой таинственности, исполненных философской многозначительности и в этом плане - трагедийно-возвышенных, вознесенных над бытом в сферу драматических проблем человеческого бытия» (БЕРДНИКОВ 1984: 112). И если в раннем творчестве снижение, обытовление образов и мотивов Достоевского носит скорее пародийный характер, то в зрелом творчестве оно отражает сущность чеховского творчества, его видения человека, чеховской «антропологии» - сознательное перенесение высоких философских проблем в периферийные области культуры (СИЛАРД 1997: 286), то есть в сферу жизни обыкновенного человека.

Алексей Лаптев, таким образом, может рассматриваться как продолжение образа Алеши Карамазова; жизнь чеховского героя - это судьба Алеши в «миру», в сфере «мирской», повседневной жизни, куда, в сущности, и отправил своего героя Достоевский. Однако в чеховском продолжении темы Достоевского усматривается и существенное различие между писателями: «опрощение» героя Достоевского вместе с тем выявляет ослабление, истощение внутреннего потенциала образа, первоначально задуманного писателем ${ }^{10}$. То есть, по Чехову, в условиях

10 Заменив в данном утверждении слова «герой», «писатель» на понятия «личность», «творец», угадывается широкий онтологический аспект чеховской антропологии: в этом смысле образ Алеши, задуманный и созданный писателемтворцом Достоевским, его милый и близкий сердцу Зосимы «лик» - это чистый, возвышенный, богоподобный образ человека, изначально задуманный и сотворенный Богом-Творцом, человек как «образ Божий», тогда как Алексей Лаптев 
«мира» происходит превращение «героя» в «раба», жаждущего добра и свободы, но слабого и безвольного.

Тема рабства, тесно связанная с образом Лаптева, в качестве лейтмотива постоянно возвращается в повести. Герой сам неоднократно называет себя рабом и характеризует свою жизнь как рабское состояние: «я раб, внук крепостного» (ЧЕХОВ 1977б: 75), «миллионы и дело, к которому у него не лежала душа, испортят ему жизнь и окончательно сделают из него раба», «и ему, и этой собаке мешало уйти со двора, очевидно, одно и то же: привычка к неволе, к рабскому состоянию» (там же: 89-90). При этом тема рабства в повести сопряжена с родом, родовой принадлежностью; в этом плане необыкновенно важную смысловую нагрузку несет в произведении инвектива об «именитом купеческом роде», главным «наследием» которого является насилие, обезличение и духовное рабство, передающиеся из поколения в поколение, от отца к сыну: «Какой там именитый род? - проговорил Лаптев, сдерживая раздражение. - Именитый род! Деда нашего помещики драли, (...) отца драл дед, меня и тебя драл отец. Что нам с тобой дал этот твой именитый род? Какие нервы и какую кровь получили мы в наследство? (...) Я родился от затравленной матери, с детства я забит и запуган!..» (там же: 80). И далее: «Да не принадлежи я к вашему именитому роду, будь у меня хоть на грош воли и смелости, я давно бы швырнул от себя эти доходы и пошел бы зарабатывать себе хлеб. Но вы в своем амбаре с детства обезличили меня! Я ваш!» (там же: 81). Принадлежность к роду вместе с тем связана с обреченностью, невозможностью вырваться из рабства рода, освободиться от власти крови. Проблема «дурной наследственности» в чеховском произведении также может быть соотнесена с романом «Братья Карамазовы», где принадлежность к роду Карамазовых изначально предопределяет сущность каждого из его представителей, даже Алеши: «...мы все, Карамазовы, такие же (насекомые - Д. К.), и в тебе, ангеле (Алеше - Д. К.), это насекомое живет и в крови твоей бури родит» (ДОСТОЕВСКИЙ 1991: 122); «Ты, Алешка, ты святой, тихоня (...), девственник, а уж такую глубину прошел (...). Ты сам Карамазов, ты Карамазов вполне - стало быть, значит же что-нибудь порода и подбор» (там же: 91). «Карамазовская кровь» у Достоевского является одним из художественных оформлений темной стороны человеческой природы, «зверя в человеке» (Полоцкая), живущего рядом с ангелом и противодействующего ему даже в душе Алеши.

У Чехова также наблюдается глубокое проникновение в противоречивость человеческой природы, только проявляется она на уровне «приземленном»: борьба противоположных начал в душе человека (в данном случае, стремление Лаптева к свободной жизни и невозможность

является художественным оформлением человека, утратившего «в мире» свой божественный потенциал, свой «образ и подобие». 
вырваться из рабства) в чеховском художественном мире артикулируется, как правило, в формах повседневной жизни, что, однако, не делает эту проблему менее значимой, менее трагичной на уровне отдельной человеческой личности. Присутствие темного начала в душе героя в чеховской повести оформляется в фигуре черной собаки, которая в восприятии Лаптева становится символом рабства, рабского состояния: «...он всё стоял и не уходил, и спрашивал себя: „Что же меня держит здесь?” И ему было досадно и на себя, и на эту черную собаку, которая валялась на камнях, а не шла в поле, в лес, где бы она была независима, радостна. И ему, и этой собаке мешало уйти со двора, очевидно, одно и то же: привычка к неволе, к рабскому состоянию...» (ЧЕХОВ 1977б: 89-90).

Вместе с тем мотив (черной) собаки с некоторым видоизменением появляется уже в самом начале произведения, как «грязный пудель» в кабинете доктора Белавина: «кабинет его с подушками на диванах, с кипами старых бумаг по углам и с больным грязным пуделем под столом...» (там же: 9). С одной стороны, вариативное повторение одного и того же мотива формирует своего рода кольцевую композицию произведения, усиливающую ощущение закрытости, безысходности. С другой стороны, ассоциативный ряд доктор - (грязный) пудель - черная собака отсылает нас к другому произведению мировой литературы - к «Фаусту» Гете, где в обличье черного пса (пуделя) является доктору Мефистофель: «Фауст: Заметил, черный пес бежит по пашне? (...) Вагнер: Обыкновенный пудель, пес лохматый...» (ГЁТЕ: ч. I, «У ворот»). Таким образом, с самого начала в глубине произведения присутствует демоническое, которое, однако появляется здесь не в какой-либо выразительной форме, скажем, явно выраженной бесноватости или одержимости, но в гораздо более скрытом виде, опасность которого заключается именно в его незримости, незаметности. Чехов выявляет повседневную пошлость демонических сил (ср. НАЗИРОВ 2005: 167), и в этом плане он, с одной стороны, согласен с Достоевским, изобразившим в «Братьях Карамазовых» дьявола как пошлого приживальщика, с другой - идет дальше Достоевского, так как представляет зло не в четко очерченном виде внешней проекции (двойника), а обличает демоническое, скрывающееся под привычными формами повседневной жизни, которое, истощая внутренние силы личности, повергает ее (личность) в духовное рабство ${ }^{11}$.

Подводя итог вышесказанному, образ Алексея Лаптева в повести «Три года» может рассматриваться как своего рода чеховское прочтение и продолжение судьбы Алеши Карамазова, в котором выявляется одна из особенностей художественной антропологии Чехова: человек, «образ Божий», в условиях «мира» утрачивает свой богоподобный облик, свою божественную сущность, изначально замысленную и сотворенную БогомТворцом, что приводит к опустошению жизни, истощению жизненной

\footnotetext{
${ }^{11}$ Подробнее о демоническом в повести «Три года» см. КОМЯТИ 2018: 78-87.
} 
энергии, разочарованию, резигнации. Вместе с тем в фигуре Лаптева выявляется и другой краеугольный камень чеховской антропологии, а именно принципиальная роль выбора в судьбе человека. Да, родовая принадлежность и «дурная наследственность» предрасполагают к «рабству», но согласие на рабство или отказ от него - это индивидуальный выбор отдельного человека. Лаптеву также предоставляется выбор между свободной жизнью и рабством (ср. «Что же меня держит здесь?»), но по слабости воли он не может отважиться на решающий шаг, требующий огромной духовной силы, не может совершить «подвига решимости оттолкнуться от всех безопасных берегов» (БЕРДЯЕВ 1985: 140), вследствие чего его жизнь остается в замкнутом кругу «дурной бесконечности» механически повторяющегося времени ${ }^{12}:$ «...быть может, придется жить еще тринадцать, тридцать лет...» (ЧЕХОВ 1977б: 91) ${ }^{13}$. Таким образом, Чехов подчеркивает ответственность человека за свой выбор: какими бы ни были внешние условия, человек всегда обладает возможностью свободного выбора, и этот выбор конституирует человека как личность. Такое видение человека и основополагающая роль выбора в становлении личности сближает Чехова с представителями раннего экзистенциализма и позволяет приобщить творчество Чехова к процессу становления экзистенциалистской мысли, идущего от Кьеркегора и Ницше до современного экзистенциализма и персонализма.

\section{Литература}

БЕРДНИКОВ Г. (1984) Чехов и Достоевский // Вопросы литературы, 1984, №2, 105-150.

БЕРДЯЕВ Н. (1985) Смысл творчества (опыт оправдания человека) // Собрание сочинений в 2-х томах. Т. 2. Paris: Ymca-Press, 1985.

ГЁТЕ И. (1960) Фауст. Москва, Государственное издательство художественной литературы, 1960. Пер. Бориса Пастернака. http://lib.ru/POEZIQ/GETE/faust.txt (дата обращения: 2021.06.10.)

12 О цикличности времени и других особенностях временной структуры повести см. КОМЯТИ 2018: 31-45 и 90-95.

${ }^{13}$ В этом плане весьма интересным является наблюдение Т. Сабо, согласно которому тема «случайного семейства», появляясь в «Безотцовщине» Чехова и романе Л. Улицкой «Искренне ваш Шурик», сопрягается с кольцевой структурой, ассоциирующейся со средневековым сюжетом «пляска смерти». Как показывает исследовательница, как в чеховском произведении, так и в романе Улицкой в центре такой кольцевой композиции находится слабый и бесхарактерный герой, а окружающих его людей одного за другим уносит смерть (САБО 2016). Как мы видим, в повести «Три года» также появляется кольцевая композиция, наряду с ослаблением характера главного героя, а мотив цикличности в произведении тесно связан с мотивом смерти: умирает Нина, сестра героя, умирает его маленькая дочь, подходит к концу жизнь старика-отца, а в конце повести сообщается о близкой кончине старшего брата Федора. 
ГРОМОВ М.П. (1989) Книга о Чехове. Москва: Современник, 1989. http://apchekhov.ru/books/item/f00/s00/z0000021/st038.shtml (дата обращения: 2021.05.30.)

ДОСТОЕВСКИЙ Ф.М. (1991) Братья Карамазовы // Достоевский Ф. М. Собрание сочинений в 15 томах. Т. 9. Ленинград: Наука, 1988-1996.

ДОСТОЕВСКИЙ Ф.М. (1994) Дневник писателя. 1876. // Достоевский Ф. М. Собрание сочинений в 15 томах. Т. 13. Ленинград: Наука, 1988-1996.

ИВАНОВ Вяч. (1989) Трагедия - миф - мистика. // Вяч. Иванов. Собрание сочинений IV. Брюссель: Foyer Oriental Chrétien, 1989. 483-588.

КОМЯТИ Д. (2018) Поэтика и антропология подтекста в прозе А.П. Чехова. Диссертация. Печ, 2018. https://pea.lib.pte.hu/handle/pea/18018

КРАЙНИЙ А. (Гиппиус 3.) О пошлости // Литературный дневник (1899-1907). СПб: изд. М.В. Пирожкова, 1908. 213-224. https:/gippius.com/doc/articles/oposhlosti.html (дата обращения: 2021.05.28.)

ЛИТОВЧЕНКО М.В. (2017) А.П. Чехов и Ф.М. Достоевский: диалог культур // Мир науки, культуры, образования. №6 (67), 2017. 504-507. https://cyberleninka.ru/article/n/a-p-chehov-i-f-m-dostoevskiy-dialog-kultur/viewer (дата обращения: 2021.06.12.)

НАЗИРОВ Р.Г. (2005) Достоевский и Чехов: Преемственность и пародия // Назиров Р.Г. Русская классическая литература: сравнительно-исторический подход. Исследования разных лет: Сборник статей. Уфа: РИО БашГУ, 2005. 159-168.

ПОЛОЦКАЯ Э.А. (1971) Человек в художественном мире Достоевского и Чехова // Достоевский и русские писатели. Традиции, новаторство, мастерство: Сборник статей (сост. В. Я. Кирпотин). Москва: Советский писатель, 1971. 184-245.

САБО Т. (2016) От «случайного семейства» к «безотцовщине» (Перечитывая Ф. М. Достоевского, А. Чехова, Л. Улицкую) // Чжан, Бяньгэ (ред.) Достоевский и судьба человечества сегодня. Пекин, 2016. 99-108.

СИЛАРД Л. (1997) К персонализму у Чехова (Николай Бердяев) // Anton P. Čehov - Philosophische und religiöse Dimensionen im Leben und im Werk. Hrsg. V. B. Kataev, R.-D. Kluge, R. Nohejl, München: Verlag Otto Sagner, 1997. 285-291.

ЧЕХОВ А.П. (1976) Письма. Т. З. Октябрь 1888-декабрь 1889 // Полное собрание сочинений и писем в тридцати томах. Москва: Наука, 1976.

ЧЕХОВ А.П. (1977а) Письма. Т. 5. Март 1892-1894 // Полное собрание сочинений и писем в тридцати томах. Москва: Наука, 1977.

ЧЕХОВ А.П. (1977б) Сочинения. Т. 9. 1894-1897 // Полное собрание сочинений и писем в тридцати томах. Москва: Наука, 1977.

ЧУДАКОВ А.П. (1971) Поэтика Чехова. Москва: Наука, 1971.

“Two novels of one biography": "Three years" by A.P. Chekhov and “The Brothers Karamazov" by F.M. Dostoevsky. In contemporary Chekhov studies the significance of Dostoevsky's creative heritage in Chekhov' artistic world is increasingly comprehended. They attempt to reveal and interpret intertextual connections with Dostoevsky's novels, embedded in the subtext of Chekhov's works. On the one hand, common themes and problems that bring writers closer together are revealed, on the other hand, Chekhov's polemical 
rethinking of Dostoevsky's legacy is noted. Connected with this tendency the article deals with comparative analysis of Chekhov's story "Three Years" and Dostoevsky's novel “The Brothers Karamazov”. In this work we try to identify and interpretate the allusions and parallels hidden in Chekhov's story.

Keywords: Chekhov, Dostoevsky, intertextuality, artistic anthropology, personality 